\title{
Stakeholder Strategy and Design Alignment Framework for Design Science Research - A Study in the Context of VR-Aided Marketing and Sales
}

\author{
Jani Holopainen \\ University of Helsinki \\ jani.m.holopainen@helsinki.fi
}

Petri Parvinen

University of Helsinki

petri.parvinen@helsinki.fi

\author{
Osmo Mattila \\ Swedish University of \\ Agricultural Sciences \\ osmo.mattila@slu.se
}

Tuure Tuunanen

University of Jyväskylä

tuure@tuunanen.fi

\author{
Essi Pöyry \\ University of Helsinki \\ essi.poyry@helsinki.fi
}

\begin{abstract}
This study introduces a framework to align various perceptions and objectives that different stakeholders have at the beginning of a Design Science Research (DSR) process and consolidate them into stakeholders' strategies and theory-ingrained design artifacts. We coin this framework as Stakeholder Strategy and Design Alignment (SSDA). As an application area, we concentrate on a Virtual Reality (VR) application designed for marketing and sales purposes. The empirical testing of the framework shows that the marketing and sales potential of the application are, indeed, perceived very differently among three stakeholder groups: company representatives, developers and customers. In addition to the introduction of a new DSR framework, the study sheds light to the applicability of VR technologies for marketing and sales use.
\end{abstract}

\section{Introduction}

The objectives of the Design Science Research (DSR) are to create rigorously developed Information System (IS) design knowledge and valuable societal or business impact. To reach those goals, DSR researchers have developed a variety of methods. For example, the focus of DSR Methodology [51] has been on building theory-ingrained artifacts and seeking technological rigor and design knowledge as generalizable outcomes. The framework provides a model for the artifact development process. The evolution of the method has continued by the development of deeper frameworks for single steps of the process. For instance, a Framework for Evaluation in Design Science Research (FEDS) [59] has become a tool that is often used to improve the rigour of the evaluation phase.

Action Design Research (ADR) [57] has been introduced to improve the relevance of the DSR to organizations by combining the classical Action Research and Design Research veins. ADR highlights organizational value instead of building the artifacts and technological rigor and, thus, it has focused on the weaknesses of the DSR Methodology. More recently, the solution-based probing [9] has become an attempt to highlight the issue of solution objectives definition, which is also considered in both DSR Methodology and ADR. While the DSR Methodology is said to concentrate too much on building the artifacts and technological rigor and while the ADR deals with rather narrow solution objectives (organizational value), the solution-based probing concentrates on broad interaction with users and stakeholders in field settings. The solution-based probing is expected to yield comprehensive design theory for a particular domain and field experiments for behavioral theory and human use of technology. The authors of solution-based probing [9] emphasize the engagement of stakeholders in search for solution objectives and the design of a solution beyond the client or user. However, the focus is more on testing and developing the solution probing in different domains and markets rather than integrating research to the process.

Often stakeholder objectives are domain-specific and they are addressed with exclusive measurements [62]. In this regard, quantitative indicators for stakeholders' requirements have been applied to align the company's and its stakeholders' objectives [16]. While most of these studies come from the domain of corporate social responsibility and environmental

URI: https://hdl.handle.net/10125/63926

978-0-9981331-3-3

(CC BY-NC-ND 4.0) 
sustainability, there is also some research on stakeholder objective alignment in the field of information systems and DSR (e.g. [3, 4, 8, 21, 48, 56]). The involvement of stakeholders has been vital for the DSR process as it iterates between two activities: designing an artifact that creates value for stakeholders and empirically investigating the performance of that artifact in its context [63]. However, as noted by Barclay and OseiBryson [3], there is a lack of solution- and objectiveoriented stakeholder management models in the DSR to integrate the research and stakeholder objectives. Moreover, these models or frameworks are completely missing in the domain of marketing and sales.

Lately, Virtual Reality (VR) technology has been increasingly used to interact with customers and many other stakeholders [26, 39]. The focus of a VR application development process, as in many other software projects, has been mostly on the client company's requirements neglecting the broader stakeholder objectives [67]. Developing interactive VR applications require specialized skills for 3D modeling, texturing and programming [66], which is a challenging domain for most managers. Therefore, in the beginning of a VR application development process, the client may have a rather limited understanding about the technical requirements for the development work. Moreover, expectations of end-users, developers and other stakeholders may vary. Commonly, the developing company has its own strategy and objectives, which become visible in the design [46]. There is a need for practitioners, researchers and developers to analyze the usefulness of VR applications and to understand what are the costs and benefits of new VR applications compared to existing systems [1, 52]. In other words, in the VR development field, there are no established strategies and designs for the system development and certain uncertainties exist. This is evident also in the VR applications designed for marketing and sales purposes. Therefore, VR provides a fruitful context for studying the first phase of a DSR process: how to align different stakeholder views when setting the objectives for a technological solution?

The purpose of this study is to introduce a Stakeholder Strategy and Design Alignment (SSDA) framework to align various perceptions and objectives that different stakeholders have at the beginning of a DSR process and consolidate them into the stakeholders' strategies and theory ingrained design artifacts. As the use of such a framework requires clearly defined objectives, we concentrate on marketing and sales objectives. The framework is empirically tested among three stakeholder groups: company representatives, developers and customers.

The contribution of the paper is twofold. First, by introducing and empirically testing the SSDA framework in the domain of marketing and sales, we introduce a new framework in DSR to incorporate the findings not only in the artifact designs but also in company and stakeholder strategies. Secondly, the study results also offer implications about the potential use of VR technologies in marketing and sales. In this regard, we give examples on how to develop design artifacts as well as strategies to incorporate and align the stakeholder objectives in a DSR process.

The paper is constructed as follows: first, we review how stakeholder objectives have been considered and aligned in the previous DSR literature. Next, we build our SSDA framework, which fundamentally uses "practical content" in the evaluation of the stakeholder objectives. The following chapters present the evaluation method and results. Finally, we discuss what implications our results have for the design artifacts and strategy development during a DSR process. We conclude with the benefits and limitations of using the SSDA framework and make suggestions for further research.

\section{Stakeholder objectives alignment}

According to Freeman [19], a stakeholder is "any group or individual who can affect, or is affected by, the achievement of an organization's objectives". Stakeholders can include both external stakeholders, such as suppliers, customers, governments, competitors, civil society organizations, local communities as well as internal stakeholders, including employees and shareholders [35]. The stakeholder management has become one of the most prevailing management models and measure to pursue competitive advantage [23].

Also the DSR has adopted the stakeholder perspective. For example, Bate and Robert [4] developed experience-based design by involving users and health-care patients in co-designing services and Almufareh et al. [1] have created a framework for helping different stakeholders to align their views on the usefulness of the technology in the healthcare industry. Braun et al. [8] applied design science guidelines in developing a business process model, notations and clinical pathways for hospitals where complex management and stakeholder models where described. Ojo et al. [48] discovered the stakeholder objectives for the smart-city DSR project from the previous project lessons. Groop et al. [21] recognized that empirical problems always involve multiple stakeholders and consequently system objectives arise from the explicit empirical analysis of the relevant stakeholders and hence the prior system objectives are often irrelevant. However, the most prevalent DSR studies considering stakeholders and their objectives revolve around the stakeholders' requirements, 
guidance, goals, assets and assessments in this regard [56].

Barclay and Osei-Bryson [3] reviewed the key challenges in IS projects being "the lack of clearly defined objectives, mismatched stakeholders' expectations and lack of sufficient or formal methods to aid practitioners in developing relevant performance criteria". They developed an IS project performance framework raising the project performance criteria to reflect the values of the project stakeholders. It should be noted that the study by Barclay and Osei-Bryson [3] was to develop and test the performance of a IS project design, not a system or application itself. However, based on the previous research and their empirical research they were able to introduce concrete and measurable project performance criteria for practitioners and future research for further development.

In order to improve the business performance in the IS field, i.e. the marketing and sales performance, Horkoff et al. [29] raise the creativity as one of the key drivers for the business success. The authors review various stakeholder requirements modeling techniques i.e. goal models applied in the requirements engineering. They recognize that while these models are widely studied in academia, there is still lack of practical implications i.e. model applications with practical contents. The practical content that they been involved in the model was addressing the creativity approach.

As noted by the previous literature there is a lack of stakeholder objective alignment tools. Furthermore, most of these tools are considering only general requirements, while more practical implications could be achieved only by considering more specific contents e.g. marketing and sales functions and practices. The next chapter introduces these marketing and sales functions and practices, how they are manifested by the current VR application literature, and finally how the suggested framework complements the existing DSR methods.

\section{Suggested DSR framework: Stakeholder Strategy and Design Alignment}

In order to build a framework with practical content targeting the marketing and sales objectives we apply a sales force effectiveness framework introduced by Zoltners and Lorimer [68] (Figure 1). As the original framework provides a comprehensive picture of only the sales organizations, we extend the framework to consider also internal and external stakeholders. We consider company reps (clients or system owners), developers and customers (end-user) all as internal stakeholders for a system. On the other hand, we consider that external stakeholders are those affected by the system but who are not actively involved in the development or use of it. Nevertheless, all stakeholders have an impact on the organizational as well as marketing and sales -strategies. We also suggest that it is a task for all internal stakeholders in the system development to align their strategies in order to meet the common requirements and objectives.

The suggested framework considers the DSR Methodology process. Similarly, as the DSR Methodology iterations are producing new objective and solution definitions, our suggested framework considers these outputs and integrates them into new marketing and sales -strategy definitions. This is called "effectiveness hunt" in the framework as aligned strategies and objectives are shown to contribute to the effectiveness and firm performance [36]. The suggested framework is an attempt to expand the DSR Methodology objective and solution definition -phase to organizational as well as marketing and sales -strategies. The DSR Methodology is criticized to concentrate a little too much on building the artifacts and technological rigor. The suggested framework is an attempt to offer more organizational value than the DSR Methodology initially. In this regard, the suggested framework is similar to the ADR [57], however, it also combines some elements from the solution-based probing [9].

The solution-based probing seeks to find mutually beneficial and sustainable solutions by shaping the solution definition during the development process [9]. It gives focus on the values of different stakeholders involved in the DSR process by introducing four development phases: ideate, initiate, intervene and incubate. During the ideation phase, the focus is on combining theory and practical knowledge to introduce an initial solution. During the initiation phase, a proofof-concept is prototyped with a focus on user testing. Intervene-phase is a proof-of-value -phase where the user value is validated. During the incubation phase, the system is independently used by the users and also other stakeholders to proof the value of the system and validated by the research. The authors of the solutionbased probing [9] emphasize the initiation -phase and the engagement of stakeholders in search for solution objectives and the design of a solution. In addition they emphasize the incubation -phase to demonstrate the impact of the use of the solution beyond the client / user. Nevertheless, while the solution-based probing considers broad interaction with users and stakeholders in the field settings as well as shaping the solution definition during the development process, it may lack the organizational value and focus which has been 


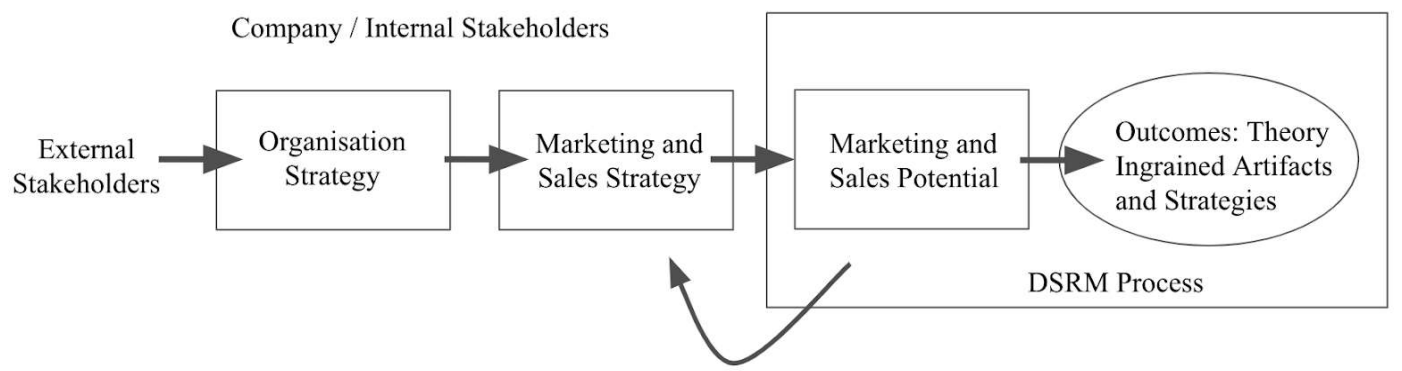

Effectiveness Hunt

Figure 1. Stakeholder strategy and design alignment framework describing the effects of DSR Methodology process on the company / internal stakeholder strategies and the design artifacts. (Adapted from Zoltners and Lorimer 2008)

claimed to be the strengths with the ADR and which our suggested model is considering by including the practical content targeting the marketing and sales objectives.

In terms of the practical content targeting the marketing and sales objectives, the framework is considering the potentials in marketing and sales. In this regard, the framework follows the marketing and sales funnel introduced by Kotler et al. [69]. The funnel consists of eight steps. The first four steps are considered usually as marketing management areas: customer awareness, brand awareness, brand consideration and brand preference. The following four steps are generally considered as sales management areas: purchase intention, purchase, customer loyalty and customer advocacy. We adopt the survey items for all of the eight steps from studies by Hansen [70] "Measuring performance at trade shows: Scale development and validation" and by Joseph et al. [71] "A measure of selling skill: scale development and validation". Each of the eight steps are represented by two survey items. "In my opinion the VR is good to..." was the overarching statement in the questioner. All sixteen (1.-16.) survey items representing different marketing and sales functions and practices can be found in the results chapter (Table 1).

By surveying these items with different stakeholders, the framework aims to show the areas where the stakeholder perceptions and objectives are aligned and where they are conflicting. The anticipated outcome of the framework would be to show the marketing and sales potentials of VR commonly acknowledged by the stakeholders, which should be addressed in the artifact design as well as in the marketing and sales strategies. The objective of the framework is also to show the stakeholder conflict areas that should be recognized and tackled in the artifact design and strategy. It should be noted that these common stakeholder perceptions no matter being positive or negative may also be misconceptions that should be corrected. As a result, the framework tries to guide to generate both theory ingrained design artifacts as well as -strategies. The framework is envisaged to provide implications to designers and managers. In addition, system, design and business researchers can use the framework to discover ways to expand their research focus to benefit practitioners.

Ultimately, the framework is a contribution to the DSR models and methods as it helps to give answers to some very common design questions: what are the marketing and sales potentials of a system and how the perceptions on these potentials differ among the various stakeholders? Previous research has shown that engaging both customers and employees has a positive influence on firm performance [33]. However, the role of external stakeholders can be expected to be increasing as information systems enable more complex business networks to evolve. By following Verhoef et al. [61], engagement can be considered as a behavioral manifestation of value. It should therefore be increased by improving processes for the participants, namely employees, customers or other stakeholders. Followed by this, almost any system or application (in addition to its main purpose and value) can be considered to have also some impact as a marketing and sales tool. In other words, most systems and applications have some sort of impact on marketing and sales, however, this is rarely considered in the design of these systems. This is also where our suggested framework makes a contribution.

We call the suggested framework Stakeholder Strategy and Design Alignment (SSDA) as it tries to consolidate the stakeholders perceptions and objectives into the stakeholders' strategies and theory ingrained design artifacts. In order to show how this is done in practice we demonstrate the use of the framework with an empirical case study. 


\section{Framework Evaluation}

VR provides an interesting context to the DSR stakeholder research because it is of increasing interest to marketers but the use of the technology is still surprisingly sparse among them [12]. It has been increasingly used as a research tool as it provides an opportunity to collect data non-invasively [64] and therefore has some benefits over traditional marketing research methods such as lab experiments and convenience sample surveys [12]. There are also an increasing number of academic studies considering the marketing and sales potential of VR technologies (e.g. $[6,7,38,58])$ but only a few $[41,44]$ using the DSR approach. Therefore, it is widely unknown how different stakeholders such as companies adopting these technologies, VR technology developers, and endcustomers, perceive the use of VR as a part of the marketing and sales funnel activities.

While there are no existing studies adopting exactly the same marketing and sales funnel items by Kotler et al. [69] and by doing so reflecting the marketing and sales potentials of VR, there are some other existing studies and findings showing the marketing and sales benefits of VR technologies. According to a recent literature review [39], research on VR in marketing use covers topics such as store interior analyses [17, 24, 45] with a focus on customer experiences and responses, new product development [47], service configurations and decision analytics by the help of gaze tracking [42, 72], interactions between companies or brand and customers, improving customer experiences by using experiential marketing [60], application feature analysis including avatars, and communication and social media research that is mostly focused on exploring future perspectives associated with social media platforms [32]. Central for the VR use is the flow [18, 40] which attributes to increased intention to purchase [2]. However, according to another recent literature review by Cowan and Ketron [12] on VR in marketing use, there is a lack of marketing research as many of the existing papers are only qualitative or self-focused.

In order to evaluate the SSDA framework, we conducted the same survey to all three stakeholder groups: company reps, developers and customers. In order to familiarize the company reps (mostly manufacturing industry CEOs, marketing- and sales managers obtained from a manufacturing industry seminar) as well as the customers (visiting customers in a manufacturing industry corner store) with the VR technology, a VR application experience was showcased to both of these groups. For the company reps, the VR application was a general visualization of a manufacturing plant accessory, whereas the VR application showed to the customers presented the cornerstone products (furniture) in their original surrounding (design artist's home studio). The developers obtained from VR software companies for the survey were already familiar with the technology so the VR application was not introduced to them, but they were surveyed with an online survey.

Based on these introductions or their previous experiences with the VR technology the participants made their judgements and answered the survey statements by using a Likert-scale from 1 to 7 (1 = Totally disagree; 2 = Strongly disagree; $3=$ Somehow disagree; $4=$ Neither agree nor disagree; $5=$ Somehow agree; $6=$ Strongly agree; $7=$ Totally agree). The means and variances were calculated for all framework statements (1-16). By using a Kolmogorov-Smirnov test, the null-hypothesis for normality was rejected with all statements as they had a significance level under 0.05 [43]. This led us to use non-parametric tests to test variance and differences between the groups. The Kruskal-Wallis test was conducted with all survey items. The pairwise Mann-Whitney test was used to detect more specifically any pairwise differences between the groups. A statistical significance level of 0.05 was applied.

\subsection{Results}

The survey data consist of 95 participants out of which $52 \%$ were customers, $25 \%$ company reps and $23 \%$ developers. On average the participants perceived the marketing and sales potentials of VR technologies very positive. In general, the company reps' perceptions on the VR technology potentials for marketing and sales were the most positive on most of the items, followed by the developers and customers with the lowest expectations. The item means and variances are reported in Table 1.

Table 1 results show that five items related to marketing activities and six items related to sales activities showed statistically significant difference between the groups $(p<0,05)$. In terms of the marketing statements (M1-M8), the items M3-M7 showed statistically significant difference between the company reps and customers $(p<0,05)$. In addition the item M4 was perceived differently between the company reps and developers $(p=0,038)$ and M7 between the developers and customers $(\mathrm{p}=0,002)$. Among all groups (company reps, developers and customers) the VR technologies were considered to be good in raising customers' awareness and attention on the products and services. On the other hand, on branding issues the VR technology shows different opinions between the groups. 
Table 1. The survey items, means, standard deviations, as well as analysis of variance by the groups.

\begin{tabular}{|c|c|c|c|c|c|c|c|c|c|c|}
\hline \multirow[b]{2}{*}{ The VR is good to } & \multicolumn{2}{|c|}{ Total } & \multicolumn{2}{|c|}{ Company } & \multicolumn{2}{|c|}{ Customer } & \multicolumn{2}{|c|}{ Developer } & \multirow{2}{*}{$\begin{array}{l}\text { Kruskal- } \\
\text { Wallis }\end{array}$} & \multirow{2}{*}{$\begin{array}{l}\text { Pairwise Mann-Whitney } \\
\quad(\mathrm{CO}=\text { company, } \mathrm{CU}= \\
\text { customer, } \mathrm{DE}=\text { developer })\end{array}$} \\
\hline & M & SD & $\mathrm{M}$ & SD & $\mathrm{M}$ & SD & $\mathrm{M}$ & SD & & \\
\hline raise customer awareness. & 5,81 & 1,23 & 6,09 & 1,00 & 5,65 & 1,39 & 5,86 & 1,04 & 0,52 & \\
\hline $\begin{array}{l}\text { get customers' attention on the subject / problem / phenomenon } \\
\text { that the products covers. }\end{array}$ & 5,68 & 1,19 & 6,04 & 1,15 & 5,52 & 1,24 & 5,64 & 1,09 & 0,15 & \\
\hline get customers interested in the company's brand. & 5,17 & 1,38 & 5,74 & 1,21 & 4,72 & 1,47 & 5,55 & 1,01 & 0,01 & CO-CU:0.010 \\
\hline get customers interested in product brand. & 5,17 & 1,30 & 6,00 & 0,95 & 4,65 & 1,35 & 5,45 & 0,96 & 0,00 & CO-CU: 0.000 ; CO-DE: 0.038 \\
\hline enhance the company image perceived by the customer. & 5,35 & 1,25 & 6,04 & 1,02 & 4,94 & 1,29 & 5,55 & 1,01 & 0,00 & CO-CU: 0.001 \\
\hline assure customers that we are a strong and solid company. & 4,80 & 1,49 & 5,43 & 1,44 & 4,52 & 1,54 & 4,73 & 1,24 & 0,05 & \\
\hline prospect new customers. & 5,29 & 1,32 & 6,04 & 1,15 & 4,98 & 1,28 & 5,18 & 1,33 & 0,00 & CO-CU: 0.002; CO-DE: 0.022 \\
\hline open discussion with prospects. & 5,44 & 1,36 & 6,35 & 0,83 & 4,98 & 1,44 & 5,50 & 1,19 & 0,00 & $\begin{array}{l}\text { CO-CU: } 0.000 \text {; DE-CU: } 0.047 \text {; } \\
\text { CO-DE: } 0.006\end{array}$ \\
\hline close & 5,58 & 1,10 & 5,91 & 1,08 & 5,27 & 1,11 & 5,91 & 0,92 & 0,27 & \\
\hline $\begin{array}{l}\text { boost the customer's decision-making process towards the } \\
\text { purchase decision. }\end{array}$ & 4,51 & 1,44 & 4,91 & 1,73 & 4,35 & 1,35 & 4,45 & 1,30 & 0,01 & CO-CU: 0.049; DE-CU: 0.038 \\
\hline get the customer to share positive experiences with us with others. & 5,44 & 1,30 & 5,96 & 1,07 & 4,98 & 1,39 & 5,91 & 0,92 & 0,00 & CO-CU: 0.018; DE-CU: 0.013 \\
\hline
\end{tabular}

In terms of the sales funnel statements ( $\mathrm{S} 1-\mathrm{S} 8)$, the items S1, S2, S4-S6 and S8 showed statistically significant difference between the company reps and customers $(p<0,05)$. In addition, the items $\mathrm{S} 1$ and $\mathrm{S} 2$ were considered different between the company reps and developers $(\mathrm{p}=0,022$ and $\mathrm{p}=0,006)$. Items $\mathrm{S} 2, \mathrm{~S} 4-\mathrm{S} 6$ and S8 all showed difference between the developers and customers $(\mathrm{p}<0,05)$. These results indicate that the VR technology is perceived good among all groups in closing the deals and extending the cooperation with existing customers. However, to prospect and open discussions with new customers the VR technology is considered to have different potentials between the groups. The same goes with advancing sales process and word-of-mouth. Remarkably, in these two categories, the opinions between the company reps and developers match, while the company reps and developers both have different views with the customers.

All these findings and their implications to artifact designs as well as marketing and sales strategies are discussed in the next chapter.

\section{Discussion}

Rapid technology development and pressures in competition force companies to adopt new technologies in an accelerating speed. Similarly like in the case of VR, this increases the number of external stakeholders and it becomes increasingly important to align company strategies, service system designs and practical implications to all stakeholders. New service concepts can be prototyped relatively easily with VR technologies [55] and as more purchases are likely to occur virtually, it is suggested that researchers should concentrate on virtual service quality research and utilize the features such as behavioral tracking and various analytics that the VR technology allows [12]. Further, VR has been used extensively in areas where consumers are the main target [39]. Along with the evolving technology, the use of it is expected to influence marketing and business decisions [39]. However, there are no existing studies showing which parts of the marketing and sales funnel it is preferred and do different stakeholder groups have different opinions about it. Our results showed positive perceptions among all participant groups towards the VR technology in different phases of both marketing and sales funnel. Therefore, it seems that there are no differences whether using the VR technology for marketing or sales purposes.

Perhaps the most visible finding in our results was that the company reps' perceptions on the VR technology potentials for marketing and sales were the most positive on most of the items, followed by the developers and customers with the lowest expectations. The misalignment between the system development objectives [3] as well as architecture and code [22] have been found to cause mismatched expectations among the project stakeholders and even total project failure. Following the SSDA framework (Figure 1), we suggest that in order to avoid and diminish these misalignments during a development process, the misalignments should be recognized and incorporated iteratively into the artifact design (as suggested by the existing DSR literature e.g. $[9,51,57,59])$, but also into the organizational as well as marketing and sales strategies among the different stakeholder groups. This should include also communicating about these misalignments between the stakeholders.

In our empirical case in the context of VR-aided marketing and sales we found the misalignments of expectations and perceived potentials of using the VR 
technology for marketing and sales on several items. For example, the company reps' and customers' perceptions on marketing effects concerning company image and product branding were misaligned. Also these perceptions between the company reps and developers differed. While this is quite common and well known misalignment in general in the marketing and brand management literature, (e.g. [69]), the alignment is also recognized to have a positive effect on business performance [14, 37]. This could have implications to be considered in the artifact design in terms of product and brand placement on a larger scale. Previously a study by Lee and Lee [73] found that brand placement in virtual games can raise the brand awareness and preference for both sponsor and game company brands, while at the same time it can also raise the enjoyment level for the game user. Another study by Roettl and Terlutter [53] recognized that compared with other digital media in the VR users remembered brands least, while the brand attitude was not affected by the media platform. They suggested that the higher feeling of presence and cognitive overloading in VR might be the potential factors for this finding. In most of the existing VR applications and also in our empirical case, there were the company brands present only in the VR application. The previous research and our findings suggest that the brand placements could be set outside the VR application, however, different placements and combinations should be further researched. In terms of marketing and sales strategies, the company managers should take this into consideration and find also alternative ways to promote the company image and product branding.

In terms of comparing different companies and their propositions (also considered under the marketing effects), the views of both company reps and customers as well as company reps and developers differed. The existing marketing literature has shown that web-based tools and search engines are an effective way to compare a broad array of offerings (e.g. [27, 34]). In one study in this category it was found that revealing more information and visuals converts not necessary to more clicks and profits [74]. There is only one study in the VR context suggesting that the VR can serve as a risk mitigation factor in decision making process [28], however, the design and business literature in this field is very scarce. While the general marketing literature shows the effectiveness of comparisons to increase buying intentions and eventually purchasing, there is basically no evidence from the system and design literature how this should be done in VR applications. Our empirical study showed that there are misalignment in perceptions on the comparison power of VR technologies. The research setup itself did not introduce any comparisons and with the lack of existing literature in this field, we cannot give any suggestions for the design or strategy other than this is a theme that should be considered in the future research and application development.

Among all groups (company reps, developers and customers) the VR technologies were considered to be good in raising customers' awareness and attention on the products and services. In other words, the VR technology shows shared views and potential in terms of educating customers. This finding is in line with several studies showing positive learning results from communication, education and training with the VR technology (e.g. [50]). These pedagogical perspectives should also be considered by the design. In addition, it can be a strategic question how to build customer awareness and knowledge in motivating and engaging manner [10, 54].

What it comes to the sales funnel items, the views on the VR potentials on prospecting new customers and opening discussions varied across the participant groups. A study by Dede et al. [13] suggest that the VR environment is optimal to deep learning and not necessarily to introduce something first time especially to a mass of people. In the marketing and sales literature there is some research showing the power of different technology solutions in aiding both marketing and sales especially in the context of mass media such as social media and user-generated content [49]. This could also be an avenue to the VR system and design research to demonstrate and validate the effect of social interaction and user-generated contents on prospecting new customers and opening new discussions. As our results showed misalignment in this regards, the proposition for the system design is to include social interactions elements and also user-generated content e.g. suggested solutions introduced or even built by other users in the VR environment. This should be considered also by the marketing and sales strategies to enable more user interactions and co-creation before, during and after the VR experiences.

To make customer to proceed towards deal-making by motivating and arranging meetings, the VR technology showed mixed opinions. Here both the company reps and developers were overwhelmingly more positive in their answers compared to the customers. While the marketing literature has shown that taking steps towards the final decision making and purchase can be a long and complicated journey [33], this should be also taken under consideration by the design and strategies. Here enabling and building individual journeys is the key, where the sensory marketing and sales have an increasing role [30]. The VR technology and design enable collecting and creating more sensory effects than any other existing technologies used in marketing and sales [65]. This fact 
gives multiple options for the designers. Therefore it is a strategic choice for the company what kind of journeys and sensory effect combinations are the most profitable for their business. Again, as the sensory technologies have vast opportunities, from the marketing and sales perspective the key is the use of sensorial strategies creating multi-sensory experiences and journeys so that a product or brand becomes more individual and personal to the customer [30].

The sales item "to get the customer to share positive experiences with others" was misaligned between the company reps and customers as well as between the developers and customers. The word-of-mouth requires motivation while a positive customer experience is not just enough [10]. Customer motivation is a more complex issue and it always requires better and deeper understanding of customer's latent needs [10]. Once mutual collaboration between the customers have been established it can contribute to many beautiful things such as collaborative learning, co-creation, engagement and loyalty [10]. In order to comprehend the customers' latent needs it requires long term strategic endeavors after which they can be incorporated to the design e.g. by creating multi-sensory experiences and journeys [30].

The sales item "closing a deal" was equally and positively perceived among all participant groups. This could mean that the VR technology really has a potential in sealing deals. Similarly extending company-customer cooperation was perceived as a potential sales activity among all participant groups. Yet another unsolved problem is how to scale these sales activities in VR. While many other electric and web-based e-commerce tools and platforms have been proven to work efficiently (e.g. [27, 34]), there is still lack of equipment as well as automatization in terms of behavioral and business models, artificial intelligence and machine learning with the VR applications and devices. While there is a huge potential of collecting different kinds analytics from VR experiences, there is still a lack of implementation and validation of VR data analytics in practice.

\section{Conclusions}

Our study developed and applied a SSDA framework to measure the sales and marketing potential of a system and to align the stakeholder perceptions and objectives in that regard. Survey data was collected to demonstrate the use of the framework in practice. The evaluation of the framework tests VR technology among three different stakeholder groups named companies adopting VR technologies, VR developers and customers as end-users of the technology. In the discussion -part of this study we demonstrated how the framework works in drawing design artifact and strategy implications and how this possibly contributes to more aligned stakeholder perceptions and objectives. The first contribution of this study was to introduce a framework and method on how to better align the stakeholder perceptions and objectives in a DSR process through the design artifact and strategy development. Especially incorporating the finding to organizational as well as marketing and sales strategies was a new contribution and addition to the existing DSR methods. As the study was conducted in the context of VR technologies exploring their marketing and sales potentials, the study results also contributed to the knowledge of the applicability of VR technologies for different marketing and sales purposes.

While the introduction of the framework raised more questions than was actually able to give answers, it works well in this regard and reinforced the impression: the field of VR-aided marketing and sales is quite new and unknown playground for both practitioners and researchers. The suggested framework introduces the stakeholder management as part of the design artifact and the strategy development in the DSR process. The framework also helps us to understand how by solving these multiple open questions in the field of VR-aided marketing and sales would benefit both design and strategy in the future.

While the framework is introduced in the context VR-aided marketing and sales, it could be tested also in other contexts. For an example, in order to specify some communication and media richness issues of a system one could use those practical contents as items in the framework and by doing so add multidisciplinarity in the DSR process. This could provide new ideas, questions, strategy developments and possibly even competitive advantage over other systems. Therefore, we suggest that the framework and approach should be further tested and developed not only in the context of VR-aided marketing and sales, but also with other technologies and disciplines. It would also be important to demonstrate and report how the objectives are recorded, aligned and incorporated into strategies during a real and longitudinal DSR process. Inclusion of more participants and different stakeholder groups would also give some insights of its importance.

Further testing and development is also required as our study comes with several limitations. First, choosing the items (in our case the marketing and sales funnel items) to the framework is always a question of choosing a stance or school to study some phenomenon. The results and even marketing and sales implications would be perhaps quite much different with some other items in the framework. Choosing the right items is a puzzling question not only for a researcher, but also for other stakeholders in the DSR process. For example, the chosen items would perhaps be more meaningful and 
have greater impact if they would also comply with the company's organizational as well as marketing and sales strategies.

We also recognize that as we measure perceptions, these are not necessarily objectives for a system development. Nevertheless, we talk about alignment of stakeholder objectives in the suggested framework. Our data as well as our observations from the field suggest that perceptions that are systematically different in one group compared to other are also reflecting objectives. For example, in our case the finding that company reps' perceptions on the VR technology potentials for marketing and sales were systematically more positive compared to developers and customers perceptions reflect also company reps' objectives for the system development. We leave this assumption to be further considered by the future research, however, the implications for the artifact designs and strategy considerations remain the same.

Another limitation for our study is the fact that the showcased VR application varied between the participant groups. Company reps had their own application, while both developers and customers had their own applications based on which they made their judgements. On the other hand, for the generalization of the results, such variance of applications and features might be a good thing as we were still able to find some compliances within the participant groups. Nevertheless, the future research should consider the framework as well as the marketing and sales items in various contexts with and without having the same application to all participant groups. This would also require including more participants from different stakeholder groups. Finally, the developed framework should be tested in other research contexts to further validate its applicability and utility.

\section{References}

1. Almufareh M, Abaoud D, Moniruzzaman M. Taxonomy development for virtual reality (VR) technologies in healthcare sector. . 2018:146-156.

2. Animesh A, Pinsonneault A, Yang S, Oh W. An odyssey into virtual worlds: Exploring the impacts of technological and spatial environments on intention to purchase virtual products. Mis Quarterly. 2011:789-810.

3. Barclay C, Osei-Bryson K. Project performance development framework: An approach for developing performance criteria \& measures for information systems (IS) projects. Int J Prod Econ. 2010;124(1):272-292.

4. Bate P, Robert G. Experience-based design: From redesigning the system around the patient to co-designing services with the patient. BMJ Quality \& Safety. 2006;15(5):307-310.

6. Bogicevic V, Seo S, Kandampully JA, Liu SQ, Rudd NA. Virtual reality presence as a preamble of tourism experience: The role of mental imagery. Tourism Management. 2019;74:55-64.
7. Boyd DE, Koles B. Virtual reality and its impact on B2B marketing: A value-in-use perspective. Journal of Business Research. 2019;100:590-598.

8. Braun R, Schlieter H, Burwitz M, Esswein W. BPMN4CP revised--extending $\mathrm{BPMN}$ for multi-perspective modeling of clinical pathways. . 2016:3249-3258.

9. Briggs, RO, Böhmann, T, Schwabe, G,Tuunanen, T. Advancing Design Science Research with Solution-based Probing. In Proceedings of the 52nd Hawaii International Conference on System Sciences. 2019; January.

10. Chiang C, Wei C, Parker KR, Davey B. Exploring the drivers of customer engagement behaviours in social network brand communities: Towards a customer-learning model. Journal of Marketing Management. 2017;33(17-18):1443-1464.

12. Cowan K, Ketron S. Prioritizing marketing research in virtual reality: Development of an immersion/fantasy typology. European Journal of Marketing. 2019.

13. Dede C, Salzman M, Loftin RB, Ash K. The design of immersive virtual learning environments: Fostering deep understandings of complex scientific knowledge. . 2000.

14. Dewsnap B, Jobber D. The sales-marketing interface in consumer packaged-goods companies: A conceptual framework. J Pers Selling Sales Manage. 2000;20(2):109-119.

16. Dohnalová Z, Zimola B. Corporate stakeholder management. Procedia-Social and Behavioral Sciences. 2014;110:879-886.

17. Domina T, Lee S, MacGillivray M. Understanding factors affecting consumer intention to shop in a virtual world. Journal of retailing and consumer services. 2012;19(6):613-620.

18. Faiola A, Newlon C, Pfaff M, Smyslova O. Correlating the effects of flow and telepresence in virtual worlds: Enhancing our understanding of user behavior in game-based learning. Comput Hum Behav. 2013;29(3):1113-1121.

19. Freeman RE. Stakeholder management: A strategic approach. New York: Pitman. 1984

21. Groop J, Ketokivi M, Gupta M, Holmström J. Improving home care: Knowledge creation through engagement and design. J Oper Manage. 2017;53:9-22.

22. Haitzer T, Navarro E, Zdun U. Reconciling software architecture and source code in support of software evolution. J Syst Software. 2017;123:119-144.

23. Harrison JS, Bosse DA, Phillips RA. Managing for stakeholders, stakeholder utility functions, and competitive advantage. Strategic Manage J. 2010;31(1):58-74.

24. Hassouneh D, Brengman M. Retailing in social virtual worlds: Developing a typology of virtual store atmospherics. Journal of Electronic Commerce Research. 2015;16(3):218.

26. Hoffmann H, Stefani O, Patel H. Extending the desktop workplace by a portable virtual reality system. International Journal of Human-Computer Studies. 2006;64(3):170-181.

27. Holland CP, Jacobs JA, Klein S. The role and impact of comparison websites on the consumer search process in the US and german airline markets. Information Technology \& Tourism. 2016;16(1):127-148

28. Holopainen J, Mattila O, Parvinen P, Pöyry E, Tuunanen T. Enabling sociability when using virtual reality applications: A design science research approach. . 2019.

29. Horkoff J, Maiden NA, Asboth D. Creative goal modeling for innovative requirements. Information and Software Technology. 2019;106:85-100

30. Hultén B. Sensory marketing: The multi-sensory brandexperience concept. European Business Review. 2011;23(3):256273 
32. Kane GC. The evolutionary implications of social media for organizational knowledge management. Information and organization. 2017;27(1):37-46.

33. Kumar V, Pansari A. Competitive advantage through engagement. J Market Res. 2016;53(4):497-514.

34. Laffey D. Comparison websites: Evidence from the service sector. The Service Industries Journal. 2010;30(12):1939-1954.

35. Laplume AO, Sonpar K, Litz RA. Stakeholder theory: Reviewing a theory that moves us. Journal of management. 2008;34(6):1152-1189.

36. Lawler III EE. Strategic pay: Aligning organizational strategies and pay systems. Jossey-Bass; 1990.

37. Le Meunier-FitzHugh K, Piercy NF. Does collaboration between sales and marketing affect business performance? J Pers Selling Sales Manage. 2007;27(3):207-220.

38. Li T, Chen Y. Will virtual reality be a double-edged sword? exploring the moderation effects of the expected enjoyment of a destination on travel intention. Journal of Destination Marketing \& Management. 2019;12:15-26.

39. Loureiro SMC, Guerreiro J, Eloy S, Langaro D, Panchapakesan P. Understanding the use of virtual reality in marketing: A text mining-based review. Journal of Business Research. 2018.

40. Matthews NL. Too good to care: The effect of skill on hostility and aggression following violent video game play. Comput Hum Behav. 2015;48:219-225.

41. Mattila O, Tuunanen T, Holopainen J, Parvinen P. Scaling consultative selling with virtual reality: Design and evaluation of digitally enhanced services. . 2018:385-398.

42. Meißner M, Pfeiffer J, Pfeiffer T, Oppewal H. Combining virtual reality and mobile eye tracking to provide a naturalistic experimental environment for shopper research. Journal of Business Research. 2017.

43. Metsämuuronen J. Tutkimuksen tekemisen perusteet ihmistieteissä. 2005. Jyväskylä: Gummerus Kirjapaino Oy. ;1324. 44. Metzger D, Niemöller C, Thomas O. Design and demonstration of an engineering method for service support systems. Information Systems and e-Business Management. 2017;15(4):789-823.

45. Muzellec L, Lynn T, Lambkin M. Branding in fictional and virtual environments: Introducing a new conceptual domain and research agenda. European Journal of Marketing. 2012;46(6):811826.

46. Mylopoulos J, Castro J, Kolp M. Tropos: A framework for requirements-driven software development. Information Systems Engineering: State of the Art and Research Themes, SpringerVerlag. 2000:261-273.

47. Ning Shen K, Khalifa M. System design effects on online impulse buying. Internet Research. 2012;22(4):396-425.

48. Ojo A, Curry E, Janowski T. Designing next generation smart city initiatives-harnessing findings and lessons from a study of ten smart city programs. 2014.

49. Ozuem W, Pinho CA, Azemi Y. User-generated content and perceived customer value. In: Competitive social media marketing strategies. IGI Global; 2016:50-63.

50. Parmar D, Bertrand J, Babu SV, et al. A comparative evaluation of viewing metaphors on psychophysical skills education in an interactive virtual environment. Virtual Reality. 2016;20(3):141-157.

51. Peffers K, Tuunanen T, Rothenberger MA, Chatterjee S. A design science research methodology for information systems research. J Manage Inf Syst. 2007;24(3):45-77.

52. Riva G. Virtual reality for health care: The status of research. Cyberpsychology \& Behavior. 2002;5(3):219-225.
53. Roettl J, Terlutter R. The same video game in $2 \mathrm{D}, 3 \mathrm{D}$ or virtual reality-How does technology impact game evaluation and brand placements? PloS one. 2018;13(7):e0200724.

54. Rossi C. Online consumer communities, collaborative learning and innovation. Measuring Business Excellence. 2011;15(3):46-62.

55. Saren M, Harwood T, Ward J, Venkatesh A. No title. Marketing beyond the frontier? Researching the new marketing landscape of virtual worlds. 2013.

56. Scherer S, Wimmer MA. A metamodel for the e-participation reference framework. . 2016:3-16.

57. Sein M, Henfridsson O, Purao S, Rossi M, Lindgren R. Action design research. Management Information Systems Quarterly. 2011;35(1):37-56.

58. Tussyadiah IP, Wang D, Jung TH, tom Dieck MC. Virtual reality, presence, and attitude change: Empirical evidence from tourism. Tourism Management. 2018;66:140-154.

59. Venable J, Pries-Heje J, Baskerville R. FEDS: A framework for evaluation in design science research. European journal of information systems. 2016;25(1):77-89.

60. Verhagen T, Vonkeman C, Feldberg F, Verhagen P. Present it like it is here: Creating local presence to improve online product experiences. Comput Hum Behav. 2014;39:270-280.

61. Verhoef PC, Reinartz WJ, Krafft M. Customer engagement as a new perspective in customer management. Journal of service research. 2010;13(3):247-252.

62. Wheeler D, Sillanpa M. Including the stakeholders: The business case. Long Range Plann. 1998;31(2):201-210.

63. Wieringa RJ. Design science methodology for information systems and software engineering. Springer; 2014.

64. Yee N, Bailenson JN. A method for longitudinal behavioral data collection in second life. Presence: Teleoperators and Virtual Environments. 2008;17(6):594-596.

65. Yoon K, Kim S, Han JJ, Han S, Preda M. MPEG-V: Bridging the virtual and real world. Academic Press; 2015.

66. Yu C, Lee H, Luo X. The effect of virtual reality forest and urban environments on physiological and psychological responses. Urban forestry \& urban greening. 2018;35:106-114.

67. Yu Y, Lapouchnian A, Liaskos S, Mylopoulos J, Leite JC. From goals to high-variability software design. . 2008:1-16.

68. Zoltners AA, Sinha P, Lorimer SE. Sales force effectiveness: A framework for researchers and practitioners. J Pers Selling Sales Manage. 2008;28(2):115-131.

69. Kotler, P, Rackham, N, Krishnaswamy, S. Ending the war between sales \& marketing. Harvard Business Review, 2006;84, 70. Hansen, K. Measuring performance at trade shows: Scale development and validation.

Journal of Business Research, 2004;57(1), 1-13.

71. Rentz, JO, Shepherd, CD, Tashchian, A, Dabholkar, PA, Ladd, RT. A measure of selling skill: Scale development and validation. Journal of Personal Selling \& Sales Management, 2002; 22(1), 1321.

72. Markopoulos, PM, Hosanagar, K. A model of product design and information disclosure investments. Management Science, 2017;64(2), 739-759.

73. Lee Y J, Lee Y J. Face Tracking for Augmented Reality Game Interface and Brand Placement. In International Conference on Ubiquitous Computing and Multimedia Applications, 2011;pp. 72-78. Springer, Berlin, Heidelberg.

74. Deutsch, M. The effect of life-cycle cost disclosure on consumer behavior: evidence from a field experiment with cooling appliances. Energy Efficiency, 2010;3(4), 303-315. 